\title{
Contesting Community Online: Virtual Imagery among Dutch Orthodox Protestant Homosexuals
}

\author{
Willem de Koster \\ Erasmus University, Rotterdam
}

\begin{abstract}
Whereas substantial scholarly attention has been paid to the online presentation of self, symbolic interactionist approaches are largely absent in the literature on virtual communities. Instead, recurrent questions are whether communities can exist online and whether specific online venues qualify as communities. This article aims to move beyond these dichotomous questions by studying how different meanings attached to an online venue can be understood from offline experiences. In a case study of a Dutch forum for orthodox Protestant homosexuals, two types of understanding of online community emerged from an analysis of fifteen in-depth interviews. Users struggling with stigmatization in offline life seek empathic support and have an encompassing sense of online community - the forum as "refuge." For users dealing with practical everyday questions, online contacts are part of so-called personal communities and help ameliorate offline life-the forum as "springboard." Apart from demonstrating that online forums can serve as Goffmanian backstages in two distinct ways, these results indicate it is fruitful to take a symbolic interactionist approach to uncover relationships between offline and online social life.

Keywords: backstage, Goffman, offline-online relationship, sexual minorities, stigma, virtual community, virtual imagery
\end{abstract}

Already in the early days of the field of research that might be termed "internet studies," the value of Goffman's notions on the presentation of self was recognized (Miller 1995). Since then, scholars have documented how individuals use computer-mediated communication to present "serious" or "playful" self-identities (Waskul and Douglass 1997; see also Hardey 2002 and Wynn and Katz 1997). Unsurprisingly, given the focus on disclosure of and experiments with self-identity, many recent publications on the online presentation of self have a general social

Direct all correspondence to Willem de Koster, Department of Sociology, Faculty of Social Sciences, Erasmus University, Rotterdam, P.O. Box 1738, 3000 DR Rotterdam, The Netherlands; e-mail: dekoster @fsw.eur.nl.

Symbolic Interaction, Vol. 33, Issue 4, pp. 552-577, ISSN 0195-6086, electronic ISSN 1533-8665. @ 2010 by the Society for the Study of Symbolic Interaction. All rights reserved. Please direct all requests for permission to photocopy or reproduce article content through the University of California Press's Rights and Permissions website, at http://www.ucpressjournals.com/reprintinfo.asp. DOI: 10.1525/si.2010.33.4.552. 
psychological outlook (for an overview, see, e.g., McKenna 2007:211-19). Other researchers, however, still address this subject with reference to Goffman's conceptual framework (e.g., Robinson 2007; Vaast 2007; Zhao, Grasmuck, and Martin 2008).

Whereas Goffman's ideas were seminal to internet scholarship addressing selfidentity, symbolic interactionist perspectives have been mostly neglected in the study of articulations of collectively shared identities in virtual communities (see, however, Adler and Adler 2008; Fernback 2007). This is remarkable, as a rich body of literature exists on virtual community, which has been a key concept of internet studies since Howard Rheingold published his frequently cited book The Virtual Community in 1993. In what follows I argue that the relative absence of symbolic interactionist contributions to the study of online communities is lamentable because its perspective could provide a way out of a current deadlock in this field of research.

The present study is inspired by the contributions made by symbolic interactionist approaches to the study of the offline counterparts of virtual settlements. Lyn Lofland (2003; cf. 1991) in particular has forcefully challenged the conventional belief that symbolic interactionism has little to add to our understanding of urban communities. Outlining "the contributions of the interactionist perspective to a sociological understanding of human life in settlements" (Lofland 2003:937), she has made a plea to study the diverse meanings that different groups attach to the urban environment (pp. 945-46). This approach has been deeply influenced by Anselm Strauss's classic works Images of the American City (1961) and The American City: A Sourcebook of Urban Imagery (1968). As their titles indicate, these books are concerned with "urban imagery," that is, how people see and think of their towns, instead of "what objectively was happening to American cities" (Strauss 1961:86). It is because of this focus that Lofland (2003:945) acclaims his studies: "Strauss approached his research topic in a manner that might be thought of as quintessentially interactionist: He asked about meaning," which naturally is characteristic of all varieties of symbolic interactionism (Meltzer et al. 1975:53).

Even though this focus on meaning has yet to be fully appreciated in urban studies, it has been advocated by other scholars as well. Looking back at four decades of scholarship, Hall (2003:46-47), for instance, signals that interactionists have significantly contributed to the study of "defining and giving meaning to space" (for an overview of studies on the diversity of settlement imagery, see Lofland 1998:139), and this is recognized by other scholars as well, most notably in the so-called urban culturalist perspective (Borer 2006).

In this study I aim to extend these arguments in favor of symbolic interactionist perspectives on urban settlements to their online counterparts. Thus what will be addressed in the case study below is what I have termed "virtual imagery": the meanings people attach to the online forum they participate in. Before doing so, I outline why such an approach is beneficial to the literature on virtual communities. 


\title{
OPENING THE COMMUNITY QUESTION IN INTERNET STUDIES
}

\author{
From Benchmark to Sensitizing Concept
}

The internet literature has been characterized by a marked focus on the concept of community. Whereas "Internet marketers label as a 'community' disconnected aggregations of random visitors to websites" (Wellman 2001:228), scholars active in various fields have argued that not all aggregations of people merit the community label (see, e.g., Blanchard and Markus 2004; Etzioni and Etzioni 1999:241; Fernback 1999:216; Papadakis 2003:vii). This has led many scholars to contemplate whether the community label can be applied to online groupings. Driskell and Lyon (2002), for example, aim to answer the question whether virtual communities in general are "true communities" (for overviews of the debates around questions like these, see, e.g., Fox and Roberts 1999:643-47, Matzat 2004:67, and Wilson and Peterson 2002:455-57). Others leave such wide-ranging questions aside and take an empirical approach to determine whether specific online interactions qualify as a community. Nieckarz (2005:408), for instance, conducts a literature review to distill the characteristics a community "must have" to determine whether the online interactions of people who trade recordings of live music performances constitute a community. Tellingly, his discussion sets out to answer one simple question, "Is it a community?" (p. 418).

In recent years, questions like these have been denounced, as they rely on a concept that is overly general and totalizing (Fernback 2007; Postill 2008). Taking a symbolic interactionist stance, Fernback (2007:63) argues it is more fruitful to analyze the meanings people attach to their online social relations than to ask in general terms "whether or not cybercommunity is or isn't real community." This critique does not, however, imply that research that is sensitive to the perspective of participants themselves does not exist. In fact, some studies focus on the experience of a "sense of community" online. Such an approach has been advocated by Ward (1999:96), who argues that an online aggregation "only becomes a community if [the participants] perceive it to be so, and experience the spirit of community."

Systematic empirical studies on experienced sense of community online have, however, employed a logic similar to that characteristic of other research on virtual communities. An example is a study by Blanchard and Markus (2004:66), who stress "it is important to know whether a sense of community exists in particular online settings" (emphasis added). To answer this question, they too try to use a kind of benchmark: after a literature review to establish the defining elements of a virtual sense of community, they study an online settlement to determine whether that sense of community is present. Addressing so-called MOOs - a specific type of socially oriented virtual environment-Roberts and colleagues (2002:229) ask a similar question: "Do MOOs have a sense of community?"

Even though Roberts and colleagues (2002:232) pose a dichotomous question and use a checklist of elements of a sense of community to answer it, they observe that "individuals experienced sense of community ... in different ways." Although they themselves do not discuss the implications of this observation, it seems highly 
relevant in the light of critiques on the use of the community concept in internet studies. After all, what is considered problematic is that time and again a specific conceptualization of community or sense of community is taken as a ruler to determine whether a specific online venue qualifies as a community. It might well be, however, that different online participants experience or aspire to different forms of "virtual togetherness" (Bakardjieva 2005:165-88) that might fit different understandings of community. This would open the door to an alternative approach in which the community concept is "opened" as to allow for variation. As such, it would meet the wishes of a recent critic of the community concept who argues "that researchers need to approach this question with an open mind, with the expectation that sociality may take on plural forms even within a single universe of practice" (Postill 2008:423).

What is needed, in short, is to study the virtual imagery of the participants on online forums. All too often Blumer's (1969:52) observation that researchers "are slaves to their own pre-established images" has applied to students of virtual communities. This is highly problematic, as, in Blumer's (1969:51) words, "people act toward things on the basis of the meaning that these things have for them, not on the basis of the meaning that these things have for the outside scholar" (cf. Gusfield 2003:122). This is why the present explorative study does not rely on the concept of community as a "definitive concept [providing] prescriptions of what to see" but employs it as a "sensitizing concept [suggesting] directions along which to look" (p. 148). Instead of applying a benchmark to determine whether a forum is a community, it looks for different articulations of virtual togetherness. As such, it aims to keep an open eye for the different meanings that online interactions may have for different users. And taking such a symbolic interactionist approach, it becomes possible to move beyond the mere level of description and to address the question of how to understand variation in articulations of virtual togetherness.

\section{Purposive Action and Offline Experiences}

As Bakardjieva (2005:168) argues, different articulations of virtual togetherness most likely stem from different aspirations. If the reasons people have for their online participation differ, they may experience or value different types of online togetherness. Because of a lack of research, little is known about these aspirations (Scott and Johnson 2005:3), but ideas about why people join online forums naturally do exist. Commonly cited ones are accessing information and the exchange of social support, and these can be supplemented by equally broad notions such as seeking friendship and recreation (for a review, see Ridings and Gefen 2004). Obviously, these categories are rather unspecific and therefore of limited analytic value. Moreover, in empirical research on virtual communities, aspirations to join a forum are hardly ever regarded as a form of purposive action. Normally, scholars rely on a notion of self-evident "shared interests" (see DiMaggio et al. 2001 and Wilson and Peterson 2002:449) underlying participation on a certain online venue and omit a 
thorough study of how these interests are defined by specific participants. Such a perspective obscures the possibility that different groups of members of a particular forum might have different reasons for their online activities.

To understand aspirations underlying forum participation as "reasons and purposes on the basis of which people steer their conduct" (Albas and Albas 2003:349), it is important not to limit research to the online realm (cf. Bakardjieva 2005:167-68). After all, people may participate on a certain forum because this might serve specific purposes for their offline lives. These purposes are not self-evidently related to a uniform interest shared by all forum members-they might vary between groups of users with different experiences in offline social life. Unfortunately, however, researchers to date have focused their inquiries on online interactions at the cost of potentially related offline experiences. Although it has been frequently stressed that offline contexts of online interactions should be taken into account (see, e.g., Baym 2006:86, Campbell 2004:192, Kendall 1999:70, and Robins 2000:92), this is still not a common practice, giving rise to ongoing laments about the bias toward the virtual that characterizes much internet scholarship (e.g., Hardey 2002:571; Nip 2004:409).

In short, to shed light on participants' understandings of their online interactions, it is important to take the daily life experiences of those involved into account, as forum participation might serve different purposes for people with different offline experiences.

\section{Where to Look?}

Having established what has to be addressed in the empirical analysis at the core of this article, one vital question remains: where to look? As argued by Wellman, Boase, and Chen (2002:162), focused studies are needed to provide "understanding how people use the internet to find community," especially now that research attention has shifted from documentation to analysis (Wellman 2004:127). It thus seems best to analyze the offline and online experiences of members of a specific internet forum.

This article focuses on a Dutch forum for people who identify as orthodox Protestant homosexuals. ${ }^{1}$ Naturally, many other forums could have been selected, but for several reasons this one is an apt choice. First, it is a good case to study online interactions pertaining to a collectively shared identity instead of presentations of self-identity. Second, since the aim of this article is to address forum participation as a form of purposive action, it seems wise to select a forum for people who are likely to regard their online activities as important in one way or another. In this respect it is relevant that it is frequently suggested that online forums are especially attractive for members of minority groups (see, e.g., DiMaggio et al. 2001:318; Deshotels and Forsyth 2007:212; Mehra, Merkel, and Bishop 2004:782; and Proulx and Latzko-Toth 2005:48). Moreover, this suggestion seems to be informed by the fact that sexual minorities were among the first groups to embrace the internet (Gross 2007:ix). As 
homosexuals generally take a minority position in orthodox Protestant offline contexts (Burdette, Ellison, and Hill 2005:178-81; for the Netherlands, see Peters and Vellenga 2007:73), the selected forum is likely to be a suitable case.

Third, even though "the online experiences of sexual minorities have been largely absent in the literature on cyberspace" (Campbell 2004:14), scholarship to date has identified a broad range of purposes that might be served by the online participation of sexual minorities. Munt and colleagues (2002), for instance, suggest that interactions at online venues might decrease social isolation, yield support in the process of coming out, and help negotiate membership in offline minority communities. Friedman (2007), too, mentions alleviating isolation and adds opportunities for collective action and access to information otherwise hard to come by (see also Cabiria 2008 and Mehra et al. 2004). Although these suggestions need further elaboration and contextualization, they do indicate that a forum for a sexual minority might provide a good case study because it probably features variation in reasons underlying participation.

\section{DATA AND METHODS}

At the time of the data collection, the forum at hand, RefoAnders, had nearly three hundred registered members who together had posted over twenty thousand messages. ${ }^{2}$ After permission was obtained from the administrator, these naturally occurring conversations were used for a first, explorative analysis. Because of ethical reasons this analysis is, however, not presented here. First, "group accessibility" (King 1996; cf. Eysenbach and Till 2001) is currently low: the forum initially consisted of a publicly accessible part and a part that was visible only to forum members, but later access was restricted to members only. Second, for some members the "perceived privacy" (King 1996; cf. Eysenbach and Till 2001) at the forum is high. Together this suggests it is better not to disclose forum conversations to the outside world.

After the explorative qualitative content analysis not reported here, in-depth interviews were carried out with fifteen forum members who responded to a call for participation that was posted with the administrator's permission. As Baym (2006:85) argues, it is better to use interviews to gain insight into the experiences and understandings of internet users than to merely rely on textual analyses of online venues. During the interviews, respondents were encouraged to speak freely, while it was ascertained that certain themes were addressed in each interview (cf. Charmaz 2006:28-35). Attention was paid to their experiences pertaining to their sexuality and religiosity in offline life, their reasons for their online participation, their online experiences, and the meanings they attach to the forum.

One interview took one hour; all the others lasted between one and a half and three and a half hours. Thirteen interviews were held face-to-face. These were recorded and transcribed verbatim. The two other interviews were held with the help of instant messaging software. Because the respondents put in a lot of effort, these online interviews were as extensive as the other interviews. To protect respondents' 
privacy, fictitious names are used. ${ }^{3}$ I have translated all quotes presented below from the Dutch, and in doing so I have tried to reflect the original wording as accurately as possible-just like the transcription of most conversations, this sometimes results in sentences that are not entirely fluent.

Apart from their online interactions, the forum members also organize so-called meetings and "living-room gatherings" among themselves every few months. The former involve recreational activities in public settings, while the latter take place in a room rented especially for this purpose. Whereas other studies of online forums suggest that offline meetings originating at online forums are exceptional (e.g., Bambina 2007), this does not seem to be the case for the Netherlands (cf. De Koster and Houtman 2008), most likely because the distance between forum members is relatively small in such a small country. During my research I was invited by various forum members to join these activities. I gladly accepted, and the insights I gained at a collective bowling session, dinners, and the like validated the interview findings. Nevertheless, I decided not to quote the conversations at these gatherings because forum members understood these as private.

\section{OFFLINE EXPERIENCES: HOMOSEXUALITY IN AN ORTHODOX PROTESTANT CONTEXT}

After addressing experiences in offline social life, the analysis discusses reasons for forum participation and then addresses the question how different articulations of virtual togetherness can be understood against this background.

Two types of offline experiences were revealed by an analysis of the data described above, and these are discussed below. As the aim of this section is to sketch the offline contexts of online interactions, the focus is on the experiences in offline social life up to the time the respondents joined the forum. The reader should, however, bear in mind that the offline experiences of some respondents changed during their forum membership and that these thus do not represent fixed categories.

\section{"A lonely struggle": Stigma, Isolation, and Emotional Problems}

The first type of offline experience is found exclusively among forum members who do not have a homosexual relationship - a few of those either live alone or at their parental home, and others are married to a woman. The latter provide various reasons for being married to someone they are not sexually attracted to. One is that it was simply not conceivable to some members to have a nonheterosexual relationship. Being deeply embedded in an orthodox Protestant social environment, this option was discursively excluded. As Piet states:

In retrospect I would say that I could have known that I was a homosexual. [But] for a long time, I did not recognize it as such, plainly because it did not exist as an option in the surroundings I was in. "Homo," that was a term of abuse, those were perverts, nothing else. That was how I knew it. 
Other members were aware of their sexuality before their marriage, but experienced social pressure to conform to heteronormative standards: "If you came out you were expelled for the rest of your life. So I just married" (Cees). For some, their conformism to this heteronormative social pressure was inspired by the idle hope that their sexual feelings toward men would wear off if they entered a heterosexual marriage: "I thought "maybe it will stop after some time"" (Hans).

Only Cees and Piet consider their marriage bearable - the other married forum members are considerably less positive. Menno's wife has been "very angry and sad" after she found out about his sexuality, and others report severe problems. Hans paints a grim picture: "She knows that I am homosexual, but she doesn't accept it. She has been very aggressive. ... If she threatens to cut off your 'thing,' that is very ... that really is not pleasant." René has similar experiences: his wife "said she loathes him" and she "is constantly humiliating him." René, too, anticipated physical violence: "At first my wife was apathetic and then it transformed into abusive language and threats." Because he feared for his physical well-being, he even fled his home for a short time.

These negative reactions to homosexuality are not only given by spouses of forum members; other relatives are strongly opposed as well. Piet's parents reacted with incomprehension:"'You better keep quiet about it. Don't talk about it anymore because otherwise more will come.' That was literally the reaction I got from my parents.... As if it was contagious." Condemnation by their family members is a recurring theme in these men's lives: "My mother said: 'I would rather have had a retard than a child like this.' ... My parents absolutely could not handle it" (René). Hans met with aversion as well: "My parents, brothers, and sisters ... did not want to have anything to do with me anymore.... Things got really difficult. My parents never visited me again." Such a loss of social contacts is a common experience. Menno says that his sister-in-law told his wife: "'You should go away from that man. I have always told you that he was no good and he cannot enter my house anymore." Negative experiences such as these are not limited to married men and can be found among forum members who live either alone or at their parental home as well. They, too, informed a small circle of relatives about their sexuality and encountered similar reactions of incomprehension and condemnation. According to Fred, his "family life is turned upside down," and as such "the worst case scenario" he envisioned "has come true." Joeri's parents "regard it a real problem they can hardly manage" - an experience shared by Edwin, who reports he did not receive any support from his parents, who "will never accept it."

These shared experiences fit the classical notion of stigma formulated by Goffman ([1963] 1986:3): the sexuality of these forum members is labeled an "attribute that is deeply discrediting." They all feel they have a "spoiled identity" (Goffman [1963] 1986), as they "perceive that they are labeled, stereotyped, and separated from others" (Green et al. 2005:198). However, they are "discredited" only in a narrowly defined social context. Since they fear that they would face status loss and discrimination - that is, "enacted stigma" (p. 198) - if their sexuality were known outside their family, they try to "pass" (Page 1984:4) as heterosexuals by shielding information about their homosexuality from others. Thus they are "discreditable" 
(Goffman [1963] 1986) in social contexts outside their family and fear that their stigma will be revealed.

Their general assessment is that a coming out in their religious community would have socially devastating consequences. Time and again these forum members extensively explain that the taboo surrounding homosexuality in their churches prevents them from being open about their sexuality. Foreseeing great problems, René, for example, is careful not to reveal his stigma:

I would regret it if it were disclosed, because people would revile and humiliate me. ... Imagine, for instance, that the whole church knew that you were homosexual ..., then people would not greet you anymore. Then the situation would become intolerable. I am sure they would get rid of me by annoying me.

Just like the others dealing with problems of stigma, the "fear of being thrown out" is reason for Menno to reveal himself "as little as possible."

The stigma of these forum members and the associated fear of disclosure underlie social isolation and feelings of loneliness. The relatives of these forum members not only label homosexuality as a severe problem but also rule out the possibility of discussing the issue. Joeri indicates, "There is very little communication about it. ... I never had the opportunity, the chance to tell how I experience it to be this way. They never asked me about it either." Not only are relatives unwilling or unable to empathically discuss homosexuality, they also tend to resist contact altogether. Hans concludes: "They tried to force me into social isolation." Menno, too, "felt really lonely and alone" after his family learned about his sexual feelings. Moreover, since they feel they have to shield their stigma as much as possible, they cannot discuss their sexuality openly with others.

This poses an additional problem, as they themselves have intense emotional problems about their sexuality. Without exception, they wrestle with their feelings, as these seem to contradict their religious beliefs. Like the others, Cees explains that in his view homosexuality is a flaw stemming from original sin: "We live in a broken world and homosexuals experience that brokenness." Therefore forum members like Cees regarded it as "shocking" to discover their sexuality-Fred, for instance, thought: "I am not supposed to be the way I am." Since he understood homosexuality as an "imperfection," he got a "sense of inferiority." For Menno, nevertheless, "it is part of my being, I cannot change that. I have to learn to accept that."

In short, these forum members have experiences of stigmatization and social isolation, and these problems are the more salient as they face severe personal emotional problems about their homosexuality they cannot share with others. Menno summarizes these offline experiences as "a lonely struggle."

\section{"It is all about how you do it": Dealing with Homosexuality in Everyday Life}

The daily life experiences of another group of forum members are not characterized by fear of social condemnation and intense emotional struggles. This is reflected 
in easy coming outs, which did not inspire much critique or resistance. Bas states: "It did not cause any problems.... my parents don't have any trouble with it, my family takes a positive stance," and he stresses that this differs from the negative experiences of other forum members: "That is an advantage I have over other people on the forum, that it is very easily dealt with." Bas's situation is not unique, however; more members tell such a story: "My family was quite positive, ... In that sense, it is not much of an issue in my personal life" (Karel). Tom had a similar experience: "My family is fully Christian, but they reacted positively without exception." In their own local church these members usually do not meet with grave problems either. As Harry explains: "It doesn't meet condemnation ... I am in the same situation as all other believers." Only Guus's coming out in the church fueled discontent with the clergy, but partly because of the "special" positive stance of his parents, this did not upset him.

Since they have hardly any significant negative experiences with regard to their sexuality, these forum members generally see little reason to conceal it. Just like Albert, they are "openly homosexual" - "friends, family, acquaintances, the village I come from, they all are informed about it" (Bas). As a result, they do not find themselves socially isolated. Tom, for instance, has contacts with homosexuals with a similar religious background. Others not only have companionship outside the forum but also have homosexual relationships they can engage in relatively easily because they do not feel a need to hide their sexuality. Guus, for example, does not mind "kissing [his] friend on the balcony," and Albert and Karel both live together with another man. Only Sam foresees problems if he were to disclose his sexuality outside his family, but he does not have problematic experiences of social isolation either, mostly because he can rely on people who provide various forms of support-he describes this as "being in a very luxurious position," thanks to which "his life is quite all right."

Not only do they not experience stigmatization, they do not regard their own sexuality as problematic in itself. They do not wrestle with a contradiction between their sexual feelings and their religious beliefs. As Harry sets out:

I would not call it a struggle. Personally, I have always experienced my homosexual feelings a matter of course, thus not as something creating a barrier with God.... Homosexuality never caused a religious crisis or an identity crisis.

This is reflected by the other members who do not experience stigmatization. Guus "never had questions about being homosexual," and Albert, who did have doubts in the past, now is "at rest" and accepts his sexuality. Tom, too, states that "it is not something that worries me" and echoes Bas's account that "one is a human being, a Christian, and accidentally one happens to be a homosexual."

In short, although they generally do not positively embrace their sexuality, this group of forum members does not face problems of stigmatization or emotional troubles. However, this does not mean that homosexuality is not an issue at all in their offline social lives. Being embedded in an orthodox Protestant offline social context and desiring to live faithful Christian lives, they have other, more practical questions they have to deal with: "You are simply different and that is something 
you have to go on with" (Sam). They do not emotionally struggle with their sexuality, but issues concerning everyday life are all the more relevant. Albert, for instance, states: "I think that in a responsible life one can very well be homosexual as well as Christian. That is not the issue, it is all about how one does it." In this respect, these forum members contemplate questions such as whether they would like to engage in homosexual relationships, whether these are theologically justifiable, and, if so, how to arrange these. It is, in short, about "finding ways to deal with that sexuality as a religious person" (Albert). In addition, they also consider how to address their sexuality in church. That they experience no stigmatization in their offline social lives does not mean they are insensitive to the religious context they are part of. Not only do they think about who to inform, at which moment, and in which way this is done best, they also have to occasionally guard themselves against critique. Karel, for instance, still anticipates occasional confrontations about his sexuality:

As long as I am part of a church and have a relationship, I will be asked questions, for the rest of my life. At these moments, you have to deal with it, you are made aware of it again.... And yes, that is something I take seriously. In that sense it consumes energy.

All of this is rather different from the stigmatization and emotional struggles reported above. These forum members generally do not experience social condemnation and fear of disclosure of their sexuality, and they accept their sexual feelings as they are. As a result, they face other, practical questions of how to faithfully live everyday life as a homosexual in an orthodox Protestant social context. Having discussed the different experiences these groups of forum members have about homosexuality in orthodox Protestant contexts, the reasons underlying their participation in the virtual realm are discussed in the next section.

\section{PARTICIPATION AS PURPOSIVE ACTION}

\section{"You have to get it off your chest": Seeking Emphatic Support}

For a discussion of the respondents' reasons for participating in the forum, it is important to note that those struggling with stigma see no alternatives in offline social life. First and foremost, this is because they attach great importance to their religion. Without exception, they regard their faith as "an essential element of [their] existence" (René), and they stress time and again that institutional embeddedness is of utmost importance to vitalize their religious beliefs. Second, for those who are married to a woman their religious principles prevent them from ending unpleasant marriages they would not recommend to anyone. Apart from financial reasons and fear of further isolation, they do not want to break their marriage vows because of moral reasons: "I have promised to be faithful unto death; I believe that is not something one can give up just like that" (Menno). Third, the importance they attach to their religious convictions renders them averse to the flowering Dutch gay scene. For these reasons they remain in an offline social context in which they are condemned or fear that they will be, feel alone, and cannot discuss their emotional struggles with 
their sexuality. ${ }^{4}$ This is the background against which their membership of the forum can be understood.

For starters, it is the reason they specifically chose to join RefoAnders instead of another forum. The importance the respondents attach to their religious beliefs not only steers them away from secular forums but also underlies their preference for RefoAnders compared with other forums for Christian homosexuals. In this respect, specific religious views are considered important: "What I found elsewhere was all liberal and not really corresponding to our [views]" (Piet).

On the forum of RefoAnders they seek relief for the troubles that plague them in offline social life. Because of the anonymity provided by the self-chosen usernames-which is considered "invaluable" (Menno) — they can "be out" online without fear of the negative consequences they face offline. Cees explains: "The main advantage of the forum is that you can remain nicely anonymous. .. Nobody knows who you are." Like the others who struggle with stigmatization, Edwin shares this view and believes online anonymity is "very important" to avoid negative reactions of people such as his family members: "Naturally, you want to be able to talk to each other without the whole world knowing about it, so it has to be hidden." He stresses that only that way "I can be myself on the forum"-an experience that is shared by the others, who state "it goes without saying" that they are better able to "be themselves" online than offline.

This is all the more important because it provides them with a safety valve for their emotional problems. Cees, for instance, discusses his reasons for joining the forum as follows:

I really wanted to discuss my sexuality with others. ... Sometimes, especially at the end, I felt like I was choking, I simply could not contain it. You have got something that haunts you all the time, and you cannot share it with anyone. That is so extreme, that is so frustrating. I thought, "I have to discuss it with someone." You have to get it off your chest, don't you? And therefore, for that reason I came to RefoAnders.

As Cees's words already suggest, these members do not simply want to express their feelings - this wish has an important social aspect to it. Because of their offline isolation, they seek understanding from people living under comparable circumstances. As Fred explains: "What I expected from it was some recognition ... something like 'I am no longer alone.' All the time I had been thinking I was alone, you know." This viewpoint comes forward time and again: "For me, the acknowledgment and recognition represent the added value of RefoAnders" (Menno). Repeatedly these members state that they joined the forum because they were looking for "companions in distress" - "I think you have to have it yourself to fully and clearly understand it" (Menno). Hans considered it "extremely special" to meet people who "fully understand him." This is especially important because these members are in need of "emotional support" (Hans) - they all stress that recognition is important because they were "looking for support" (Joeri): "When someone is despondent then you succor him, that simply is really important" (René). 
All in all, the forum members struggling with stigmatization and isolation were looking for empathic support when they joined the forum-a desire to be among similar others who provide support and understanding permeates their accounts of their reasons for joining the forum. Therefore their forum participation yields a great sense of relief. Because of sheer enthusiasm, Cees, for instance, does not know how to express his feelings best-he indicates that "at RefoAnders I fully came out of my shell," "it was so wonderful just to be able to say how it was," "I have simply become another person," and "it is so liberating." Moreover, their participation reduces their feelings of isolation and loneliness. Fred states, "It is of great help that there are others experiencing the same struggle." As a consequence, they learn to come to terms with themselves: "It has tremendously helped me accept myself the way I am," Cees, for instance, states.

Because of these positive results, the meaning of the forum changed for some members. This does not hold for Edwin, who still feels socially isolated in offline life and therefore remains an active member of the forum. Others, like Menno, are still active but "not as much as it used to be": "If you feel OK it recedes into the background, and if you feel less well the intensity grows" (cf. Adler and Adler 2008:42). For Fred, Piet, and Joeri, however, their participation changed more radically. The emphatic support they received on the forum helped them overcome the problem of being "discreditable"-having accepted their sexuality, they no longer fear having their stigma revealed. Joeri says, "You don't have to play hide and seek any more," and Piet is happy he "didn't receive that many negative reactions" when he made a broad coming out. Because their offline problems of stigmatization decreased, their forum use became similar to that of the group of users discussed below.

\section{"How do others deal with it?": Seeking Practical Advice}

Those who do not face problems of stigmatization and isolation in offline social life provide a different rationale for their forum membership. Nevertheless, just like the stigmatized members they are attracted to RefoAnders because of its explicit orthodox Protestant signature. They, too, have an aversion to secular forums for homosexuals and are not attracted to other forums for Christian homosexuals. It is because its "more conservative dealing with the issue of homosexuality" (Harry) that RefoAnders is preferred:

I come from a more orthodox milieu, and at [a more general forum for Christian homosexuals] ... it is very liberal, anything goes. That doesn't really fit the denomination I come from, the outlook that prevails there ... as well as my own perception. (Bas)

Although these respondents share the stigmatized members' preference for RefoAnders, they are not active on the forum for the same reasons. Tellingly, they do not attach importance to the forum's anonymity like the other members do. While recognizing "that it is important for some people," Guus "really doesn't find it interesting at all," as he "has nothing to hide." For Albert a username is "absolutely not 
important": "I just want to be frank. Everywhere I am just [full name]. I value openness," and-like Harry and Karel—Bas filled in so many personal details in his user profile that he is easily traceable: "It is simply the way I am and people may know about it. I would not mind if it were published in the newspapers, so to speak." Moreover, because these members can discuss their sexuality openly in offline life, they do not participate in the forum to give utterance to feelings that otherwise remain unexpressed: "For me it is not something like a safety valve or something like that" (Tom). As they do not struggle with stigmatization and emotional troubles, they do not look for empathic support on the forum. Tom states, "It is not that I go looking on the forum whether there are any people that might understand me so that you are supported or something like that. No that really is not why I am active on it," and Albert explains, "I don't look for that kind of safety, I already feel safe."

Whereas the stigmatized members turn to the forum because they cannot "be out" offline, the participation of these respondents is inspired by a desire to openly live as a homosexual in an orthodox Protestant context. Since they feel that they need to learn how to do this faithfully as well as practically, they turn to a forum populated by people living under similar conditions. Because others face the same questions in everyday life, they can help in a process of "personal development": "You are all homosexual, you are all Christian and you seek people among those Christian homosexuals to develop yourself, to learn from others" (Bas). Explaining what he values most in his interactions with other forum members, Harry also indicates his forum participation is about personal development instead of expressing emotional problems and receiving empathic support and understanding: "I always try to get starting points, and I stand in great need of feedback."

The questions are about how to handle day-to-day life, and to find answers they look for insightful experiences, information, and advice on practical matters. This differs from the aspirations of the members struggling with stigmatization, who say that for them "tips and advice are not really what it is about," as they attach greatest importance to "recognition and the feeling of not being alone" (Menno). Bas sets out his most important reason for his participation in RefoAnders:

I came out of the closet and then everything was all new. And then you are eager to get information, "how do others deal with it?" You think it is crystal clear, but after a while ... certain questions arise...." How do I fit my homosexuality in with Christianity?" "Can these go together?" "And in a relationship?" "How do you deal with it at home, with family, with reactions, with the church?"

As Harry puts it: "The question that keeps me busy is: in what way can I lead a chaste, Christian life? On the forum of RefoAnders I can ask that question. ... On the forum I post messages in which I put my personal questions of life into words."

A related practical question these members seek answers to on the forum is how to handle occasional queries about their sexuality in offline life:

It is important for my personal life because I just want to be an active member of a church, and in daily life in Reformed denominations you occasionally encounter people who raise questions like "how do you do that, explain, how is it 
possible?" Sometimes you can use a forum, not just because of the argumentation but to get insight into their way of thinking, so that you recognize it and it is less conflicting. (Karel)

The participation of this group of members is also inspired by the desire to help others with information and advice on issues they have sorted out for themselves. According to Tom, for instance, "being an adviser for one another is one of the objectives of the forum," and Albert strongly believes he has to help others with the process he has been through himself: "I know that there are many more homosexuals, and I want to mean something to them. ... That is a very important part of my life, it provides meaning. I consider it important, for me it is something of a mission." Karel shares this view, thinking, "Maybe I can seek interaction or just look at what the concerns of these people are. Are there any questions I asked myself earlier and for which you might give someone advice?" For Guus, too, "helping young Christian homosexuals" is "most important."

All in all, the forum members concerned with practical, everyday questions participate on RefoAnders because this enables them to draw on the experiences of those living in comparable offline situations as well as to share their own insights with others in need of advice. As such, the reasons inspiring their forum participation differ from the desire for emotional support prevalent among the forum members who struggle with stigmatization.

Although the analysis thus has revealed two distinct groups with different offline experiences and related reasons for their online participation, this does not imply that these groups are monolithic wholes. Of course, there are differences among members of both groups-some members of the latter group, for instance, stress questions about relationships, whereas others emphasize learning how to respond to queries of fellow churchgoers. What is important for the question at hand is, however, that they share a focus on practical questions that differs from the desire for emotional support characteristic of the members of the other group.

\section{COMMUNITY AT REFOANDERS}

These different reasons for participation rooted in experiences in everyday life go hand in hand with specific understandings of community at RefoAnders. Those seeking empathic support experience RefoAnders as an encompassing community, whereas the forum is part of a far less solid "personal community" for members who participate to deal with practical day-to-day issues. These understandings of community go hand in hand with specific views on symbolic boundaries and diversity.

\section{Different Understandings of Community}

Although all members appreciate associating online with people sharing their orthodox religious beliefs as well as their sexuality, important differences lie behind this similarity. For those struggling with stigmatization, this common identity 
fuels a generalized attachment to other forum members. Cees indicates that "being among like-minded people or companions in distress ... absolutely excites connectedness to each other." Edwin shares this feeling of attachment- "I feel attached to the forum itself" - and this extends to the forum members "in general": "You are connected to persons who are the same as you are, who have faith and are homosexual." This is echoed in the account of René, who experiences a "connection with RefoAnders." As such, an oft-quoted aspect of community is present among the members facing stigmatization in offline social life-there is "communal solidarity" (Komito 1998:98), "a solidarity among all those who comprise it" (Foster 1997:25; cf. Papadakis 2003:9).

The relationships with the forum population in general are not experienced to be "affect-laden" (Etzioni 2004:225) by members who use the forum to deal with practical issues instead of offline problems of stigmatization and isolation. Albert conveys he has no special attachment with other forum members in general, and Guus "never felt attached to Christian homosexuals ... simply because we happened to be on the same forum or shared the same homo-background." This is not to say that they do not experience any attachment to other forum members at all-these feelings are, however, limited to specific members with whom they associate when dealing with the questions they face. Sam, for instance, indicates that a feeling of connectedness "is not something I experience with regard to the forum, but I do when it comes to some individual members." Tellingly, Fred, whose forum use transformed from seeking emphatic support to dealing with practical issues, indicates his attachment changed over time. He confirms that he had a generalized feeling of solidarity at first, but now believes that "you have to choose your people." These are "people you get along with well" (Tom), and in this respect the members dealing with practical issues frequently speak of "friends" (Guus), "friendships" (Joeri), and "companions" (Sam).

These differences between generalized, encompassing feelings of solidarity, on the one hand, and personal companionship, on the other, are reflected when it comes to a "sense of belonging" (Blanchard and Markus 2004; Foster 1997:29; Kelemen and Smith 2001:372; Nieckarz 2005:407; Papadakis 2003:9). Those struggling with stigmatization and isolation not only feel attached to the forum and its members in general, they also have outspoken feelings of belonging. Edwin, for instance, confers that his "connectedness" makes him "feel at home" on the forum, and Menno "feels at home" because "the atmosphere at RefoAnders feels pleasant." Likewise, Cees says he "pretty much feels at home there" even to the extent that-even though "it is a weighty term"-RefoAnders feels like "a second home" to him, as "it has become part of [his] life."

The forum members whose participation is related to practical questions do not have such an emotional sense of belonging on the forum. Tom, for instance, states: "It is not like I don't have any emotions, but with regard to a forum I do think like 'get a life,' it is just a computer screen." And now that Joeri has overcome his struggles, this is reflected in his forum participation: "At a certain moment you experience a 
change and from then on it is merely pleasant to keep up personal contacts through the forum." Moreover, these members explicitly dismiss the idea of the forum being a second home to them: it is a suggestion Guus merely laughs at, and Sam says, "It is absolutely not a second home. It is sad that it is to some others, something is wrong if it is your second home." Referring to his current quest to ameliorate everyday life, Fred states: "I would rather build my own home."

These divergent understandings also come to light when the members themselves reflect on RefoAnders as a community. Although some think the community label "is a little too strong" to be applied to the forum (René), the members struggling with stigmatization embrace a discourse of community when it comes to their online interactions because they "have something in common that binds them" (Menno). Edwin is very outspoken on this matter: "Naturally, the forum is like a little city in itself, a village in itself." Later on he says: "I like it to be part of that community-it really is a community, isn't it?" This is not how those driven by practical questions see it. Some of them indicate that the forum may be a community for those dealing with stigmatization, like Albert who notes that there is "a group of people that feel safe among each other, who want to and dare to talk among each other, which they would not dare anywhere else." But, as his words already point out, this is not the meaning he himself attaches to the forum. That some of those dealing with practical questions denote the forum a community at all is only because they have a shared identity consisting of "homosexuality and Christian faith" (Harry). Others are utterly dismissive of the idea. For Guus, this is the case because "there absolutely are no common bonds"; for Sam, "[the forum members] are all individuals who give their opinion once in a while." Fred laughs while stating, "It would be way too limited, with such a pack of homosexuals among each other" to speak of community on the forum.

In short, those who struggle with stigmatization in offline social life understand the forum to be a tight-knit, encompassing community. Those addressing practical questions in day-to-day life have a less-encompassing sense of community, but nevertheless value a shared identity and report feelings of connectedness with specific fellow members. Their understanding of community resembles that of "personal communities" (Wellman et al. 1996; Wellman, Boase, and Chen 2002; Wellman et al. 2003), a concept developed by the sociologist Barry Wellman to indicate that many people nowadays are "limited-liability members of several partial communities rather than fully committed members of one all-embracing community" (Wellman and Hampton 1999:650; cf. Arnold 2007). In times of "networked individualism" (Wellman et al. 2003) and "personalized networking" (Wellman 2001), people "cycle through interactions with a variety of others" instead of "relating to one group" (Wellman et al.2003). This is precisely what can be seen among the members of RefoAnders who participate on the forum to deal with practical questions in everyday life. As they are not socially isolated in offline life, they have no generalized feelings of attachment to the forum community, but rather value contacts with "companions" and "friends" they have met on the forum-the latter being part of personal networks not confined to RefoAnders. 
These different understandings of community are not limited to the virtual realm: the offline gatherings organized around the forum are differently valued as well. Some have not been able to attend these because of practical reasons, but members of both groups do visit these offline meetings. Their offline participation reflects their specific concerns rooted in their everyday life experiences.

Those struggling with stigmatization regard offline gatherings as valuable because they provide the same sense of belonging as their online interactions do. As Hans puts it: "You feel at home among that kind of men." And just like his forum participation, René's attendance at offline meetings-which he keeps secret from his wife-is inspired by a desire to retreat from his negative experiences at home and to associate with people he feels comfortable with: "Then I really don't want to go back to the world I come from, do you understand? I belong in that world [of RefoAnders], but I live in another world.... You feel at home in that world among men and then you come back into a marriage with a shouting wife."

In line with their understanding of online community, those dealing with practical questions provide different accounts of their offline participation. They primarily value the offline meetings because of the personal contacts they have there, as a way to keep up friendships. Guus, for instance, is very clear about his visits to the RefoAnders living room: "The motivation for me is that I simply see friends of mine at that moment. [Mentions specific names.] Well, they all live that far away, you don't have time for that during the week. And that is my motivation to just visit [the meetings]."

In short, the different reasons underlying forum membership go hand in hand with different understandings of community, both online and offline. These differences are reflected in views on symbolic forum boundaries and diversity, which shed light on the way the different groups aspire to "attain and maintain" (Watson 1997:110) the kind of community they value.

\section{Symbolic Boundaries and Diversity}

To start with, forum members have different opinions about the forum's accessibility to outsiders. Those seeking empathic support desire that their communications be hidden from the outside world. They greatly appreciate the "members-only" part of the forum, reflecting their desire to retreat into a community of like-minded people. Cees states: "It is very important that not everyone and his dog can access the forum." Edwin explains: "Naturally, you want to be able to talk to each other without the whole world knowing about it, so it has to be hidden." He summarizes this position as: "I consider it important that everything is private." The members who are focused on practical questions hold different views. These state that they "are not hindered" (Fred) by the fact that nonmembers can read their contributions to the forum and that they do not care about what nonmembers can read. Joeri says: "I am aware that some people are really attached to it, and also make a plea to make a much larger part exclusively accessible to members, but no, I don't see that distinction myself." Karel states: "I consider it to be public." 
Divergent stances on boundaries also appear from opinions about so-called user groups, that is, subforums for specific groups of members such as "youngsters" or "married people." Stigmatized members use this feature, and they consider it important "because there are people who really have solidarity with each other in a small community within a larger community" (Edwin). The other forum members, however, do not participate in user groups, and some denounce these groups as "pathetic" (Guus) or "nonsense" (Bas), as they do not stimulate insights that can be used in everyday life: "Even though you don't share someone's position, you can still learn from each other" (Bas). Joeri explains, "I am a proponent of a broad forum of which people of all ages are members, precisely because you can help each other with advice and the like," and Sam adds, "Why would someone of another group not be of value to you?"

The aversion to "user groups" among the latter group of forum members is reflected in their general stance toward diversity on the forum. Because they are active online to learn about everyday questions, they value the presence of members with different characteristics: "Everyone has his own story, absolutely. And from every story you can learn something yourself" (Bas). In line with this perspective, heterosexuals are welcomed on the forum, and their presence is regarded as "all right" (Albert) as long as they do not try to impose their own views. Harry says: "I believe we need their input ... in church we are one. The 'homo question' is not about homosexuals alone." Fred explains, "I don't oppose heterosexuals on the [forum]. Not at all, because I have to deal with them in society as well," and Joeri says, "It provided me with insight into the way that a heterosexual who doesn't understand homosexual feelings looks at the phenomenon," which helped him "adjust [his] strategy." Guus, too, values the online presence of heterosexuals because "it is like practicing, isn't it? Let them go, talk to those heterosexuals and let them see what the reactions are." For Karel, this is specifically important as it helps him learn how to handle incidental critiques of his sexuality: "[Heterosexual member] is an example of someone I could meet in everyday life and who would ask me [critical questions].... But how do you handle that? [This member] is someone who put me on a track like 'all right, if someone acts like this, then I might do this."”

Those struggling with stigmatization hold different views. As virtually belonging to a group of like-minded, understanding peers is what relieves their plight, they do not want to see the cohesive community found at RefoAnders disturbed by outsiders. Only for Edwin the presence of heterosexuals is all right, but not because he himself values it: "No, that is purely for themselves. That is not of importance to us. They ask questions ... because they don't understand." Cees argues, "Properly speaking, the forum is not [for heterosexuals]," and others are more outspoken: Menno states, "Properly speaking, they don't belong [on the forum]." According to him, heterosexuals undermine the conversations between like-minded homosexuals because "they don't understand," and Hans explains he does not like their presence because "then I feel somewhat spied on."

Both groups not only disagree about the question of how to deal with heterosexuals on the forum, they also have different outlooks on diversity in viewpoints 
pertaining to homosexuality and religion. Some of those experiencing stigmatization in offline life regard divergent opinions "inconvenient" because these are "confusing" (Menno). Others "don't have troubles" (Cees) with different stances, but they do not consider it especially valuable, either, that different opinions are represented on the forum. On the other hand, the forum members dealing with practical questions highly appreciate diversity in viewpoints expressed on the forum, which "just keeps it all healthy" (Bas). They indicate that they "like to listen to other opinions" (Harry) and consider "a broad range of opinions" "helpful" (Fred) because they try to learn from their online interactions: "Even the negative things-in case I totally disagreeyield positive things [because] I think "well, that is not how I want it to be for myself"" (Fred). Guus especially values diversity in opinions because it aids the "youngsters" he aims to help: "In the beginning it is nice to find some like-minded people, and people you can talk to. But if you are young you want to move ahead, you know. Then you want to look at 'how is it to have a relationship. Can I live with that or not?"”

In line with their positive stance toward plurality in viewpoints, these members value debates on the forum: "A forum is of course a place where people have discussions. The moment you only allow people with a specific opinion to the forum it is no longer a forum, then it is a meeting-place of people who think alike, then the discussion is gone" (Piet). They "like fierce discussions" instead of "chit-chat" (Albert) because these bring "clarity" (Fred), "break taboos," (Guus), and help "critically look at your own points of view" (Joeri). Those aiming to find empathic support among likeminded people take a different stance, as fierce debates impede their sense of community. Hans argues, "It doesn't get you anywhere," and when asked for an example of a negative experience on the forum, Edwin tells about a forum member "who really tried to bring down my views on certain things," which he "regarded as very mean." According to Edwin, the expression of contrary opinions "only leads to more discussion ... [and] forces you in a defensive position," which undermines the support on the forum.

In short, the two groups have different understandings of community and hold different views about group boundaries and diversity. Those struggling with stigmatization embrace a clearly bounded, homogeneous community in which they can take refuge and find empathic support. Those seeking insight into day-to-day issues look for informational instead of emotional support. As they value their personal contacts with specific forum members as nodes in their personal community networks, their sense of community is not undermined if the forum resembles an open, heterogeneous place for deliberation. Such a forum configuration suits their aspirations best; if the forum is open, accessible, and characterized by diversity and fierce debate, they have opportunities to learn from their online interactions.

\section{CONCLUSION AND DISCUSSION}

Inspired by symbolic interactionist contributions to urban sociology, the analysis presented above indicates it is fruitful to take the offline and online experiences of forum members into account to study different forms of virtual imagery. In doing 
so, different understandings of online community can be distinguished, and it can be understood why users value a certain type of community by addressing their reasons for participation that are rooted in experiences in offline everyday life. As such, the analysis presented in this article adds strength to Fernback's (2007) plea to embrace a symbolic interactionist perspective by taking seriously the meanings people attach to their online interactions. Instead of developing a benchmark to determine whether a forum can be characterized as a community (e.g., Nieckarz 2005), it is of theoretical interest to uncover the connection between different forms of virtual togetherness and experiences in offline social life. To gain further insight into these interrelationships, it is important to pay attention to the reasons forum members have for their online participation. The results presented in this article indicate it does not suffice to simply assume that online venues are attractive because they provide access to like-minded people with shared interests. Instead, online participation should be analyzed as purposive action: different experiences in offline life proved to underlie different reasons for forum participation. The fact that specific forms of purposive action underlie specific definitions and uses of the forum indicates once more that meaning does not emanate from the forum itself-it should be studied why specific actors attach certain meanings to it (cf. Blumer 1969:3-4).

At a more concrete level the analysis presented in this article is in line with research that indicates that online forums are attractive to people struggling with stigmatization and isolation in offline social life (e.g., Adler and Adler 2008; McKenna and Bargh 1998). The results demonstrate that their forum membership relieves some of their problems because they receive empathic support online and that their participation inspires an encompassing sense of online community (cf. De Koster and Houtman 2008), which goes hand in hand with a desire to keep the forum homogeneous and clearly bounded. For this group the forum can be termed a refuge. Moreover, Goffman's ([1963] 1986) notion of stigma proved of analytic value, as those not struggling with problems of stigmatization in offline life have a different understanding of community and different views on forum boundaries and diversity. Those facing practical questions on how to faithfully live as a homosexual in an orthodox Protestant context regard the people they associate with on the forum as part of their personal communities, and for them the forum itself can be called a springboard, as their online participation helps them ameliorate their offline lives.

Furthermore, these findings shed light on the idea that internet forums provide Goffmanian ([1959] 1990) backstages. Examining the literature, two different notions can be distinguished. In line with Goffman ([1963] 1986:81), some authors put forward that online forums function as backstages in the sense that the stigmatized can reveal their stigma there and "openly seek out one another for support and advice" (Deshotels and Forsyth 2007:212; Quinn and Forsyth 2005:198-99). As such, online forums are backstages enabling the stigmatized to live a "double life," shielding their identity in offline life and being open about it online (Adler and Adler 2008:50). Others, however, mean something entirely different when dealing with 
the subject of online backstages. Referring to Goffman as well, Mukerji and Simon (1998:259), for instance, denote online venues as backstages because these enable rehearsal to manage or respond to public life, and Munt, Bassett, and O'Riordan (2002:135) put forward that the Web site they studied is used as a backstage because participants "solicit opinion and debate on the appropriate behaviour and values" to build connections in their local communities. Thus some scholars label online forums as backstages because these can be places individuals can retreat to, whereas others speak of online backstages as venues in which people can obtain insights and practice for offline front-stage performances.

These differences can be understood by taking the offline experiences of forum users into account. For both groups at RefoAnders the forum has backstage characteristics: it is a venue apart from their front-stage offline social lives in which their performances are given (Goffman [1959] 1990). These offline performances, however, greatly differ, and this underlies different uses of the online backstage. The refuge function of the forum for those struggling with stigmatization is a backstage in the first sense, whereas the springboard function for those facing practical everyday questions closely resembles a backstage in the second sense. This extends Goffman's ([1959] 1990:127-29) observation that the function of stages varies in relation to different performances; not only can a specific place switch from front-stage to backstage and vice versa, it can also function in distinct ways as a backstage for groups giving different front-stage performances. Moreover, the findings indicate that those desiring the backstage to be a place to retreat to require it to be closed off from the front-stage, whereas those looking for practical insights do not. As the latter regard it as a place for deliberation, they even welcome members of their front-stage audience backstage.

Finally, this article might inspire further inquiries into the online activities of sexual minorities. The research presented here might be a first step toward disentangling the diverse uses of online forums that are mentioned in the literature on nonreligious sexual minorities. As such, it could inspire efforts to develop a contextualized theoretical understanding of online participation of members of sexual minorities. This empirically modest case study suggests that internet forums are valued as backstages in the sense of "safe harbors" (Cabiria 2008) by stigmatized sexual minorities, and as backstages to prepare for offline social life (Munt et al. 2002) by members facing practical day-to-day questions about their sexuality, but naturally these findings are in need of elaboration. Do members of sexual minorities in tolerant, progressive contexts, for instance, use online forums to arrange dates (McLelland 2002; Mowlabocus 2008) or to celebrate post-traditional identities (Friedman 2007), and which forms of virtual and offline togetherness does this inspire? What are the offline experiences of members of sexual minorities that stimulate them to participate online to engage in collective action aimed at social change, and does this go hand in hand with a strong sense of cohesive community (Friedman 2007)? Future research rooted in the symbolic interactionist tradition may address questions like these to further our insight into the interplay of offline and online social lives. 
Acknowledgments: The author thanks two anonymous reviewers and the editor Mark D. Johns as well as Stef Aupers, Dick Houtman, Jeroen van der Waal, and Paula Dragosh for their constructive comments on an earlier version of this article.

\section{NOTES}

1. The forum members describe themselves literally as "homosexuals" (in Dutch:homoseksuelen) or "people who have homosexual feelings" (mensen met homogevoelens). To reflect these definitions as accurately as possible, I have translated their identification as homosexual, even though gay is the prevailing term in English. This is because the term gay is sometimes used in Dutch with reference to the secular Dutch gay scene these participants are averse to.

2. Some have argued that the name of a forum should be omitted from scholarly publications to protect its members (King 1996). In this case study there are, however, two reasons not to replace the forum name with a pseudonym. First, none of the members of RefoAnders wanted the forum name replaced, and various members even argued against it. Second, hiding a forum for a minority group could unethically contribute to further marginalization of that group (Bassett and O'Riordan 2002:243-44). RefoAnders stands for "Reformatoric yet Different."

3 . Fourteen respondents are male, one is female. To protect the anonymity of the female respondent she has been given a male pseudonym, and masculine pronouns are used to refer to her.

4. None of the respondents considered "healing" their sexuality - which is promoted in certain religious contexts (see Erzen 2006, Robinson and Spivey 2007, and Wolkomir 2001) —a feasible option.

\section{REFERENCES}

Adler, Patricia A. and Peter Adler. 2008. "The Cyber Worlds of Self-Injurers: Deviant Communities, Relationships, and Selves." Symbolic Interaction 33(1):33-56.

Albas, Cheryl A. and Daniel C. Albas. 2003. "Motives." Pp. 349-66 in Handbook of Symbolic Interactionism, edited by L. T. Reynolds and N. J. Herman-Kinney. Walnut Creek, CA: AltaMira.

Arnold, Michael. 2007. "The Concept of Community and the Character of Networks." Journal of Community Informatics 3(2). Retrieved October 30, 2007, from http://www.ci-journal.net/ index.php/ciej/article/view/327/315.

Bakardjieva, Maria. 2005. Internet Society: The Internet in Everyday Life. London: Sage.

Bambina, Antonina. 2007. Online Social Support: The Interplay of Social Networks and ComputerMediated Communication. Youngstown, NY: Cambria.

Bassett, Elizabeth H. and Kate O'Riordan. 2002. "Ethics of Internet Research: Contesting the Human Subjects Research Model." Ethics and Information Technology 4(3):233-47.

Baym, Nancy K. 2006. "Finding the Quality in Qualitative Internet Research." Pp. 79-87 in Critical Cyberculture Studies, edited by D. Silver and A. Massanari. New York: New York University Press.

Blanchard, Anita L. and M. Lynne Markus. 2004. "The Experienced 'Sense' of a Virtual Community: Characteristics and Processes." The DATA BASE for Advances in Information Systems 35(1):65-79.

Blumer, Herbert. 1969. Symbolic Interactionism: Perspective and Method. Berkeley: University of California Press.

Borer, Michael Ian. 2006. "The Location of Culture: The Urban Culturalist Perspective." City and Community 5(2):173-97.

Burdette, Amy M., Christopher G. Ellison, and Terrence D. Hill. 2005. "Conservative Protestantism and Tolerance toward Homosexuals: An Examination of Potential Mechanisms." Sociological Inquiry 75(2):177-96.

Cabiria, Jonathan. 2008. "Virtual World and Real World Permeability: Transference of Positive Benefits for Marginalized Gay and Lesbian Populations." Journal of Virtual Worlds Research 1(1):1-13. 
Campbell, John Edward. 2004. Getting It On Online: Cyberspace, Gay Male Sexuality, and Embodied Identity. New York: Harrington Park.

Charmaz, Kathy. 2006. Constructing Grounded Theory: A Practical Guide through Qualitative Analysis. Los Angeles: Sage.

De Koster, Willem and Dick Houtman. 2008. “'Stormfront is like a second home to me': On Virtual Community Formation by Right-Wing Extremists." Information, Communication, and Society $11(8): 1153-75$.

Deshotels, Tina H., and Craig J. Forsyth. 2007. "Postmodern Masculinities and the Eunuch.” Deviant Behavior 28(3):201-18.

DiMaggio, Paul, Eszter Hargittai, W. Russell Neuman, and John P. Robinson. 2001. "Social Implications of the Internet." Annual Review of Sociology 27:307-36.

Driskell, Robyn Bateman and Larry Lyon. 2002. "Are Virtual Communities True Communities? Examining the Environments and Elements of Community." City and Community 1(4): $373-90$.

Erzen, Tanya. 2006. Straight to Jesus: Sexual and Christian Conversions in the Ex-Gay Movement. Berkeley: University of California Press.

Etzioni, Amitai. 2004. "On Virtual, Democratic Communities." Pp. 225-38 in Community in the Digital Age: Philosophy and Practice, edited by A. Feenberg and D. Barney. Lanham, MD: Rowman and Littlefield.

Etzioni, Amitai and Oren Etzioni. 1999. "Face-to-Face and Computer-Mediated Communities, a Comparative Analysis." Information Society 15(4):241-48.

Eysenbach, Gunther and James E. Till. 2001. "Ethical Issues in Qualitative Research on Internet Communities." British Medical Journal 323(7321):1103-5.

Fernback, Jan. 1999. "There Is a There There: Notes toward a Definition of Cybercommunity." Pp. 203-20 in Doing Internet Research: Critical Issues and Methods for Examining the Net, edited by S. Jones. Thousand Oaks, CA: Sage.

- 2007. "Beyond the Diluted Community Concept: A Symbolic Interactionist Perspective on Online Social Relations." New Media and Society 9(1):49-69.

Foster, Derek. 1997. "Community and Identity in the Electronic Village." Pp. 23-37 in Internet Culture, edited by D. Porter. London: Routledge.

Fox, Nick and Chris Roberts. 1999. "GPs in Cyberspace: The Sociology of a Virtual Community." Sociological Review 47(4):643-71.

Friedman, Elisabeth Jay. 2007. "Lesbians in (Cyber)Space: The Politics of the Internet in Latin American On- and Off-Line Communities." Media, Culture, and Society 29(5):790-811.

Goffman, Erving. [1963] 1986. Stigma: Notes on the Management of Spoiled Identity. New York: Simon and Schuster. . [1959] 1990. The Presentation of Self in Everyday Life. London: Penguin Books.

Green, Sara, Christine Davis, Elana Karshmer, Pete Marsh, and Benjamin Straight. 2005. "Living Stigma: The Impact of Labeling, Stereotyping, Separation, Status Loss, and Discrimination in the Lives of Individuals with Disabilities and Their Families." Sociological Inquiry 75(2):197-215.

Gross, Larry. 2007. "Foreword.” Pp. vii-x in Queer Online: Media, Technology, and Sexuality, edited by K. O'Riordan and D. J. Phillips. New York: Lang.

Gusfield, Joseph R. 2003. “A Journey with Symbolic Interaction.” Symbolic Interaction 26(1):119-39.

Hall, Peter M. 2003. "Interactionism, Social Organization, and Social Processes: Looking Back and Moving Ahead." Symbolic Interaction 26(1):33-55.

Hardey, Michael. 2002. "Life beyond the Screen: Embodiment and Identity through the Internet." Sociological Review 50(4):570-85.

Kelemen, Mihaela and Warren Smith. 2001. "Community and Its 'Virtual' Promises: A Critique of Cyberlibertarian Rhetoric.” Information, Communication, and Society 4(3):370-87.

Kendall, Lori. 1999. "Recontextualizing 'Cyberspace': Methodological Considerations for On-Line Research." Pp. 57-74 in Doing Internet Research: Critical Issues and Methods for Examining the Net, edited by S. Jones. Thousand Oaks, CA: Sage. 
King, Storm A. 1996. "Researching Internet Communities: Proposed Ethical Guidelines for the Reporting of the Results." Information Society 12(2):119-27.

Komito, Lee. 1998. "The Net as Foraging Society: Flexible Communities." Information Society 14(1):97-106.

Lofland, Lyn H. 1991. "History, the City, and the Interactionist: Anselm Strauss, City Imagery, and Urban Sociology." Symbolic Interaction 14(2):205-23.

- 1998. The Public Realm: Exploring the City's Quintessential Social Territory. New Brunswick, NJ: Aldine Transaction.

_. 2003. "Community and Urban Life." Pp. 937-74 in Handbook of Symbolic Interactionism, edited by L. T. Reynolds and N. J. Herman-Kinney. Walnut Creek, CA: AltaMira.

Matzat, Uwe. 2004. "Cooperation and Community on the Internet: Past Issues and Present Perspectives for Theoretical-Empirical Internet Research." Analyse und Kritik 26(1):63-90.

McKenna, Katelyn Y. A. 2007. "Through the Internet Looking Glass: Expressing and Validating the True Self." Pp. 205-21 in The Oxford Handbook of Internet Psychology, edited by A. N. Joinson, K. Y. A. McKenna, T. Postmes, and U.-D. Reips. Oxford: Oxford University Press.

McKenna, Katelyn Y. A. and John A. Bargh. 1998. "Coming Out in the Age of the Internet: Identity 'Demarginalization' through Virtual Group Participation.” Journal of Personality and Social Psychology 75(3):681-94.

McLelland, Mark J. 2002."Virtual Ethnography: Using the Internet to Study Gay Culture in Japan." Sexualities 5(4):387-406.

Mehra, Bharat, Cecelia Merkel, and Ann Peterson Bishop. 2004. "The Internet for Empowerment of Minority and Marginalized Users." New Media and Society 6(6):781-802.

Meltzer, Bernard N., John W. Petras, and Larry T. Reynolds. 1975. Symbolic Interactionism: Genesis, Varieties, and Criticism. London: Routledge and Kegan Paul.

Miller, Hugh. 1995. "The Presentation of Self in Electronic Life: Goffman on the Internet." Paper presented at Embodied Knowledge and Virtual Space Conference, Goldsmiths' College, University of London, June 1995. Retrieved August 25, 2009, from http://www.ics.uci. edu/ jpd/classes/ics234cw04/miller2.pdf.

Mowlabocus, Sharif. 2008. "Revisiting Old Haunts through New Technologies: Public (Homo)Sexual Cultures in Cyberspace." International Journal of Cultural Studies 11(4):419-39.

Mukerji, Chandra and Bart Simon. 1998. "Out of the Limelight: Discredited Communities and Informal Communication on the Internet." Sociological Inquiry 68(2):258-73.

Munt, Sally R., Elizabeth H. Bassett, and Kate O'Riordan. 2002. "Virtually Belonging: Risk, Connectivity, and Coming out On-Line." International Journal of Sexuality and Gender Studies 7(2-3):125-37.

Nieckarz Jr., Peter P. 2005. "Community in Cyber Space? The Role of the Internet in Facilitating and Maintaining a Community of Live Music Collecting and Trading." City and Community 4(4):403-23.

Nip, Joyce Y. M. 2004. "The Relationship between Online and Offline Communities: The Case of the Queer Sisters." Media, Culture, and Society 26(3):409-28.

Page, Robert M. 1984. Stigma. London: Routledge and Kegan Paul.

Papadakis, Maria C. 2003. "Computer-Mediated Communities: The Implications of Information, Communication, and Computational Technologies for Creating Community Online." Arlington, VA: SRI International.

Peters, Ruud and Sipco J. Vellenga. 2007. "Homoseksualiteit in Orthodox-Religieuze Kring: Islam en Protestantisme." Justitiële verkenningen 33(1):70-82.

Postill, John. 2008. "Localizing the Internet beyond Communities and Networks." New Media and Society 10(3):413-31.

Proulx, Serge and Guillaume Latzko-Toth. 2005. "Mapping the Virtual in Social Sciences: On the Category of 'Virtual Community." Journal of Community Informatics 2(1):42-52.

Quinn, James F. and Craig J. Forsyth. 2005. "Describing Sexual Behavior in the Era of the Internet: A Typology for Empirical Research." Deviant Behavior 26(3):191-207. 
Rheingold, William. 1993. The Virtual Community: Homesteading on the Electronic Frontier. Reading, MA: Addison-Wesley.

Ridings, Catherine M. and David Gefen. 2004. "Virtual Community Attraction: Why People Hang out Online." Journal of Computer-Mediated Communication 10(1). Retrieved July 13, 2007, from http://jcmc.indiana.edu/vol10/issue1/ridings_gefen.html.

Roberts, Lynne D., Leigh M. Smith, and Clare Pollock. 2002. "Mooing Till the Cows Come Home: The Search for Sense of Community in Virtual Environments." Pp. 223-45 in Psychological Sense of Community: Research, Applications, and Implications, edited by A. T. Fisher, C. C. Sonn, and B. J. Bishop. New York: Kluwer Academic/Plenum.

Robins, Kevin. 2000. "Cyberspace and the World We Live In." Pp. 77-95 in The Cybercultures Reader, edited by D. Bell and B. M. Kennedy. London: Routledge.

Robinson, Christine M. and Sue E. Spivey. 2007. "The Politics of Masculinity and the Ex-Gay Movement." Gender and Society 21(5):650-75.

Robinson, Laura. 2007. "The Cyberself: The Self-Ing Project Goes Online, Symbolic Interaction in the Digital Age." New Media and Society 9(1):93-110.

Scott, James K. and Thomas G. Johnson. 2005. "Bowling Alone but Online Together: Social Capital in E-Communities." Journal of the Community Development Society 36(1):1-18.

Strauss, Anselm L. 1961. Images of the American City. New York: Free Press.

- ed. 1968. The American City: A Sourcebook of Urban Imagery. Chicago: Aldine.

Vaast, Emmanuelle. 2007. "The Presentation of Self in a Virtual but Work-Related Environment: From Protagonists to Fools." Pp. 183-99 in Ifip Volume 236: Virtuality and Virtualization, edited by K. Crowston, S. Sieber, and E. Wynn. Boston: Springer.

Ward, Katie J. 1999. "Cyber-Ethnography and the Emergence of the Virtually New Community." Journal of Information Technology 14(1):95-105.

Waskul, Dennis and Mark Douglass. 1997. "Cyberself: The Emergence of Self in On-Line Chat." Information Society 13(4):375-97.

Watson, Nessim. 1997. "Why We Argue about Virtual Community: A Case Study of the Phish.Net Fan Community." Pp. 102-32 in Virtual Culture: Identity and Communication in Cybersociety, edited by S. G. Jones. London: Sage.

Wellman, Barry. 2001. "Physical Place and Cyberplace: The Rise of Personalized Networking." International Journal of Urban and Regional Research 25(2):227-52.

- 2004. "The Three Ages of Internet Studies: Ten, Five and Zero Years Ago.” New Media and Society 6(1):123-29.

Wellman, Barry and Keith Hampton. 1999. "Living Networked On and Offline." Contemporary Sociology 28(6):648-54.

Wellman, Barry, Jeffrey Boase, and Wenhong Chen. 2002. "The Networked Nature of Community: Online and Offline." IT and Society 1(1):151-65.

Wellman, Barry, Janet Salaff, Dimitrina Dimitrova, Laura Garton, Milena Gulia, and Caroline Haythornthwaite. 1996. "Computer Networks as Social Networks: Collaborative Work, Telework, and Virtual Community." Annual Review of Sociology 22:213-38.

Wellman, Barry, Anabel Quan-Haase, Jeffrey Boase, Wenhong Chen, Keith Hampton, Isabel Díaz, and Kakuko Miyata. 2003. "The Social Affordances of the Internet for Networked Individualism." Journal of Computer-Mediated Communication 8(3).

Wilson, Samuel M. and Leighton C. Peterson. 2002. "The Anthropology of Online Communities." Annual Review of Anthropology 31:449-67.

Wolkomir, Michelle. 2001. "Wrestling with the Angels of Meaning: The Revisionist Ideological Work of Gay and Ex-Gay Christian Men.” Symbolic Interaction 24(4):407-24.

Wynn, Eleanor and James E. Katz. 1997. "Hyperbole over Cyberspace: Self-Presentation and Social Boundaries in Internet Home Pages and Discourse." Information Society 13 (4):297-327.

Zhao, Shanyang, Sherri Grasmuck, and Jason Martin. 2008. "Identity Construction on Facebook: Digital Empowerment in Anchored Relationships." Computers in Human Behavior 24(5): 1816-36. 